\title{
RISK MANAGEMENT PLAN
}

\section{U.S. Department of Energy \\ National Nuclear Security Administration \\ Nevada Operations Office \\ Office of Environmental Management \\ Las Vegas, Nevada}

Approved by:

Bobbie K. McClure

Date

Program Integration Coordinator

Carl P. Gertz

Date

Assistant Manager

Environmental Management 


\section{CONTENTS}

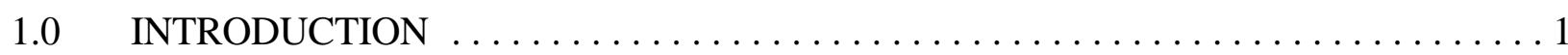

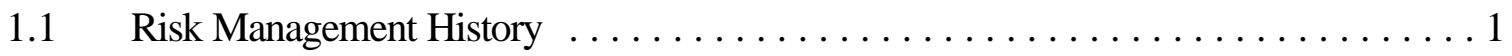

$1.2 \quad$ Purpose and Scope Summary $\ldots \ldots \ldots \ldots \ldots \ldots \ldots \ldots \ldots \ldots \ldots \ldots \ldots \ldots$

2.0 BACKGROUND AND RISK MANAGEMENT $\ldots \ldots \ldots \ldots \ldots \ldots \ldots \ldots \ldots \ldots \ldots$

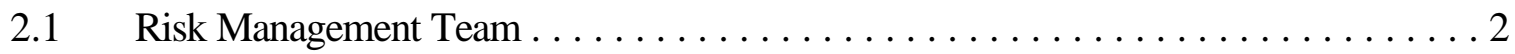

2.2 Responsibilities for Risk Management ......................... 2

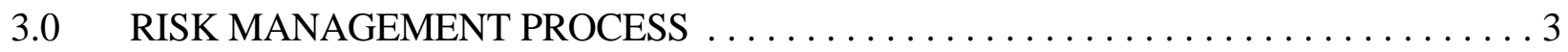

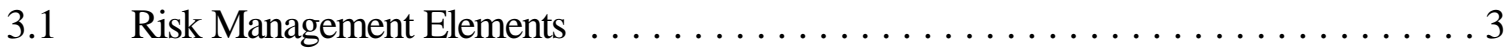

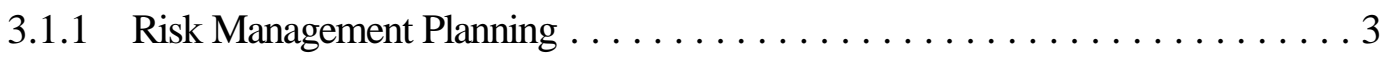

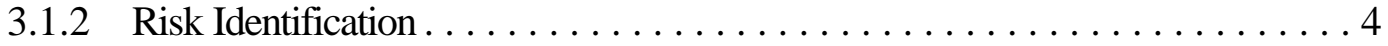

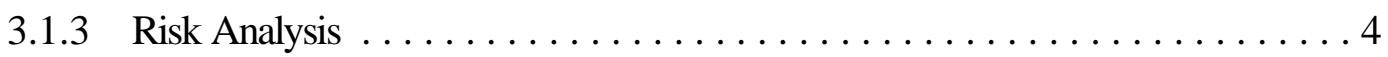

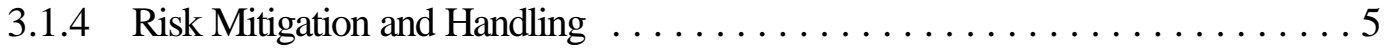

3.1.5 Risk Tracking, Reporting, and Closure $\ldots \ldots \ldots \ldots \ldots \ldots \ldots \ldots \ldots$

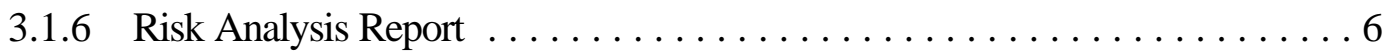

3.1.7 Baseline Change Control Proposal (BCCP) $\ldots \ldots \ldots \ldots \ldots \ldots \ldots \ldots$

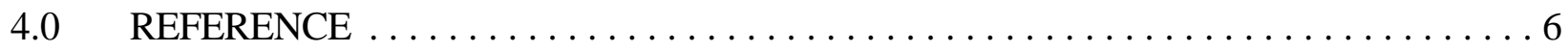

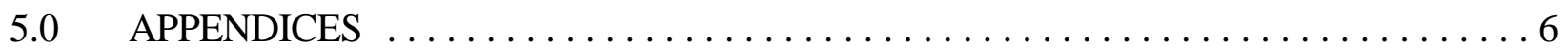

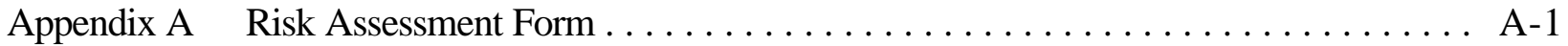

Appendix B Risk Screening Guidelines . . . . . . . . . . . . . . . . . . . . .

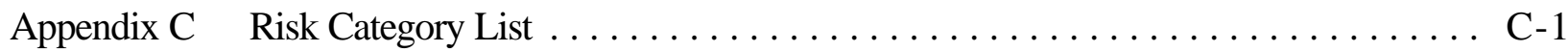

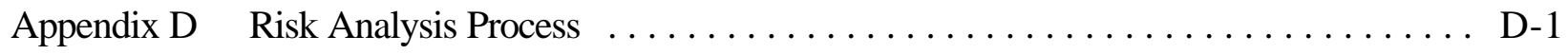




\subsection{INTRODUCTION}

The Risk Management Plan (RMP) for the U.S. Department of Energy, National Nuclear Security Administration Nevada Operations Office (NNSA/NV) Environmental Management (EM) program defines the scope and process for the identification, assessment, and management of risks which could impact the implementation of the program and/or its relevant projects. Risk Management will include assessable risks that could potentially jeopardize successful completion of projects and will also address risks that potentially jeopardize human health and the environment. The objective of this plan is to define the strategy to manage program-related risks throughout the remainder of the life cycle such that there is acceptable minimal impact on cost and schedule, as well as operational performance. The RMP follows DOE Order 413.3 and its associated guidance on program and project management principles.

The RMP is considered a "living document" which will be updated as needed to ensure that previously identified risks are managed effectively and new risks are quickly identified and managed thoughout the life cycle.

\subsection{Risk Management History}

Each respective life cycle baseline (LCB) within the NNSA/NV EM program utilizes a Monte Carlo risk model (and other tools as appropriate) to simulate the effects of uncertainty on costs and time. Variables considered include regulatory and stakeholder requirements, escalation, funding constraints, technology, resource availability, laboratory capacity, and unexpected field conditions. Results are included in each LCB.

\subsection{Purpose and Scope Summary}

The purpose of this RMP is to establish the concept and define the process to assure that NNSA/NV EM programs and projects incorporate appropriate, efficient, cost-effective measures to mitigate the impact of program-and/or project-related risks. In addition, it describes the roles and responsibilities of program personnel in performing the risk management functions, and defines reporting and tracking requirements for risk-related information. 
The product of this risk analysis will be a risk analysis report listing the various risks with their classification, mitigation and handling strategies, impact on cost and schedule, and action items. The risk management process will identify potential risk sources; assess individual risks and impacts on performance, cost, and schedule; evaluate alternative approaches to mitigate high and moderate risks; develop action plans to handle individual risks; and interface risks with other programs and/or projects.

Risk management and risk assessment will be consistent with DOE Orders 430.1 and 413.3 and their associated guidance documentation. The RMP will remain valid for the life cycle of the program and/or projects and will be under configuration control with revisions to be conducted as required and approved.

\subsection{BACKGROUND AND RISK MANAGEMENT}

The environmental liabilities left by years of nuclear testing are addressed by the NNSA/NV EM program. These liabilities include costs for environmental restoration and waste management activities, as well as the identification and management of the associated risks. The costs are collectively referred to as the U.S. Department of Energy's “environmental mortgage." Activities required to address this mortgage have risks that must be managed to ensure accomplishment of the work scope within defined cost and schedule parameters without creating risk to workers, the public, and the environment. Risk management is the terminolgy used to encompass the activities required to minimize risk to program and project activities. NNSA/NV EM will identify, analyze, mitigate, track, and trend risk by programatic category, e.g., Environmental Restoration and Waste Management. Each program will develop its own Risk Management Plan and assess risk at the program and project level. Mitigation will occur at the applicable level and tracking will be at the program level.

\subsection{Risk Management Team}

NNSA/NV EM programs will consist of a risk management program will consist of Project Managers, supporting functional managers, subject matter experts as appropriate, and key project controls staff members. 


\subsection{Responsibilities for Risk Management}

Division Directors are responsible for ensuring that programmatic and project risks are identified, analyzed, mitigated, tracked, and trended.

Project Managers are responsible for identifying project risks, developing risk mitigation strategies, and overseeing implementation of risk mitigation techniques.

Contractor Project Managers are responsible for execution of risk mitigation strategies and techniques and identifying possible impacts as well as tracking and trending risk.

Program Integration is responsible for developing and updating programmatic Risk Management Plans and configuration management of the plans as well as providing support to programs and projects.

\subsection{RISK MANAGEMENT PROCESS}

The risk management process will follow the established criteria in DOE Orders 430.1 and 413.3 and their associated guidance. This process will be documented by a risk assessment form contained in Appendix A.

\subsection{Risk Management Elements}

The risk management process includes the following six elements:

- $\quad$ risk management planning;

- risk identification;

- risk analysis;

- risk mitigation; and

- $\quad$ risk tracking, reporting, and closure.

\subsubsection{Risk Management Planning}

Program and project activities are evaluated to determine if there is a potential for risk in the proposed or defined baseline (scope, schedule, and cost) or other programmatic activities. To facilitate this 
process, the Division Director and/or project manager reviews the activity against a set of criteria through risk screening guidelines, as provided in Appendix B. If all answers are acceptable, no risk management is required. If any answer is Yes, then the risk management process is initiated through a selection of assessable elements. These elements are discrete programmatic or project-specific entities against which an effective risk analysis may be performed and results evaluated to make necessary decisions.

Guidance for the determination of assessable elements in support of each program and/or project is contained in its respective lower-tiered analysis document.

\subsubsection{Risk Identification}

Risk identification is an organized approach for determining which events are likely to affect a program, and for documenting the characteristics of the events that may happen with a basis as to why this event is considered a risk. Identification relies on the skill, experience, and insight of programmatic and/or project personnel and subject matter experts. Risks to be identified include both internal and external risks that come from both negative and positive sources. This process may be accomplished by causeand-effect evaluation that indicates whether an outcome should be avoided or encouraged. Key sources of input to risk identification include:

- $\quad$ activity or descriptions (e.g., scope statements),

- other activity or planning documents (e.g., WBS, cost/time estimates, procurement plans, or hazard lists), and

- $\quad$ historical information (e.g., project files, recollection, estimates, and lessons learned).

Methods and tools to initiate risk identification can vary depending on resource availability. The preferable method is a risk category list, which is contained in Appendix C. Other tools include process flow charts, risk/activity templates, interviews with subject matter experts, and team brainstorming. The results of risk identification are clear statements of risk with corresponding bases. Risk identification information is contained within each program's project execution plan as well as each programs lifecycle baselines. 


\subsubsection{Risk Analysis}

This process contains the risk assessment parameters for each risk, and, when completed, provides the necessary information for any further handling of the risk. The risk analysis is accomplished by evaluating both the probability and occurrence of risk against established criteria. Risk determination is performed using a variety of quantitative or qualitative techniques, dependent upon complexity and preference. In either case, a risk factor is calculated in order to determine a risk level. Information relative to risk factors and risk levels is contained in each program's specific project execution plan. Detailed analyses are contained in each program's lifecycle baseline documentation.

Specific risk (i.e., first-of-a-kind risk [FOAK]) carries marginal costs which must be considered for innovative projects (e.g., research and development), technologies, structures, systems, and/or components. Identified FOAK risks will generally be assigned a greater frequency range/numerical value in the "Very Likely" area with a consequence severity consistent with "Critical" or "Crisis" unless it can be substantiated otherwise.

\section{Qualitative Approach}

This methodology uses a risk level matrix which allows independent assessment of the probability and consequence of a risk. In addition, it provides qualitative definition of basis for the risk and risk level.

\section{Quantitative Approach}

This methodology uses quantitative values to determine a quantitative risk factor. The quantitative approach provides a qualitative definition for the basis of risk using quantitative inputs for risk level, and it provides finer grading within the risk levels. This method is useful for prioritization activities, either among alternatives where numerous risks exist within the individual risk levels, or among risks in determining where to allocate resources.

Risk levels are contained within each program's lifecycle baselines. Steps for each method are defined in Appendix D.

Other risk quantification tools include expected monetary value, expert judgment, simulation, and decision trees. Descriptions of these methods are provided in DOE Order 413.3 guidance. 


\subsubsection{Risk Mitigation and Handling}

Risk handling is the identification of a course of action or inaction selected for the purpose of effectively managing a given risk. All identified risk shall be handled. Specific handling methods should be selected after personnel have determined the probable impact on the program and/or project. Responses to risk fall into four categories: reduce or mitigate, accept, avoid, or transfer. Each completed risk analysis will contain a recommended risk-handling process. It will be a graded approach to establish risk handling priority and a level of effort for risk handling, with the basis being the risk level as determined by frequency of risk occurrence and severity of risk consequences. Risk priority and resource availability determine the execution sequence of each risk mitigation. Top-level details regarding risk mitigation are contained within each program's project execution plan, with supporting analyses in the program's lifecycle baseline.

\subsubsection{Risk Tracking, Reporting, and Closure}

Risk reporting is the documentation of risk identification, quantification, handling, and impact determination activities. Risk tracking typically monitors several types of information to include milestones, cost data, various types of studies, and action items. Depending on the program and/or project, management indicators can include periodic status reports, performance measures, and action items.

Tracking will be conducted by the program and/or projects as applicable to ensure that risks are appropriately mitigated/minimized

\subsubsection{Risk Analysis Reporting}

Risk handling will be documented as part of the program's risk management plan as well as program or project baselines. This section of the lifecycle baselines will be updated as new risks are identified or existing risks are modified or deleted.

\subsubsection{Baseline Change Control Proposal (BCCP)}

Risk analysis is a component of the NNSA/NV EM baseline change control process, and impacts will be reflected, as appropriate, into the programmatic risk management plan or baselines through the change control process. 


\subsection{REFERENCE}

U.S. Department of Energy. October 2000. Draft Program and Project Management.

U.S. Department of Energy. October 2000. Draft Project Management Practices.

\subsection{APPENDICES}

This plan contains four appendices to guide project managers in assessing risk and includes information relative to risk screening, risk categorization, risk analysis process, and risk assessment documentation. 


\section{APPENDIX A - RISK ASSESSMENT FORM}

\begin{tabular}{|l|l|}
\hline Date: & Assessed Element (Optional): \\
\hline Risk Identification Number: & Risk Category (Optional): \\
\hline Risk Title: & Risk Type (Optional): \\
\hline & Responsibility (Optional): \\
\hline & KASE \# (Optional): \\
\hline
\end{tabular}

A. Statement of Risk:

(State Event and Risk)

B. Probability: (State probability and basis that the risk will come true w/o credit for risk handling strategy.)
O Very Unlikely
$\bigcirc$ Unlikely
O Likely
O Very Likely
$(\mathrm{P} \leq 0.1)$
$(0.2 \leq \mathrm{P} \leq 0.4)$
$(0.5 \leq \mathrm{P} \leq 0.7)$
$(0.8 \leq \mathrm{P} \leq 1.0)$

$\begin{array}{ll}\text { C. Consequence: } & \begin{array}{l}\text { (State consequences an } \\ \text { risk handling strategy.) }\end{array}\end{array}$

Worst Case Cost Impact:

Worst Case Schedule Impact:

○ Negligible

○ Marginal

O Significant

(Cs

$(\mathrm{C} \leq 0.1)$

$(0.2 \leq \mathrm{C} \leq 0.4)$

$(0.5 \leq \mathrm{C} \leq 0.7)$

$(0.8 \leq \mathrm{C} \leq 1.0)$

$(\mathrm{C} \geq 0.9)$

D. Risk Level:

$\bigcirc$ Low

Moderate

$\bigcirc$ High

$\mathrm{P} \times \mathrm{C}=$ Risk Factor $(\mathrm{RF})$

$\mathrm{RF}=$

E. Risk Handling Strategies:

\begin{tabular}{|c|c|c|c|c|c|c|c|}
\hline \multirow{2}{*}{$\begin{array}{l}\text { Risk Handling } \\
\text { Approach }\end{array}$} & \multirow{2}{*}{$\begin{array}{c}\text { Risk Handling Strategy (RHS) Description and } \\
\text { Bases }\end{array}$} & \multicolumn{3}{|c|}{ Reduced } & \multicolumn{2}{|c|}{ Implementation } & \multirow{2}{*}{$\begin{array}{l}\text { Tracking \# } \\
\text { (Optional) }\end{array}$} \\
\hline & & $P$ & C & Risk & Cost & $\begin{array}{l}\text { Schedul } \\
\mathrm{e}\end{array}$ & \\
\hline & & & & & & & \\
\hline
\end{tabular}


NNSA/NV-781

Risk Management Plan

Rev. 0

F. Residual Risk Impact:

Cost Consequence:

Schedule Consequence:

Best

Most Likely

Worst

G. Description of Residual Risk:

H. Schedule to Cost Conversion Factor:

$\$$

per unit

I. Affected WBS:

J. Additional Comments (Optional): 


\section{APPENDIX B - RISK SCREENING GUIDELINES}

\begin{tabular}{|c|c|c|c|}
\hline \multirow{2}{*}{ Risk Screening Criteria } & \multicolumn{3}{|c|}{ Potential for Risk? } \\
\hline & No & Low & Yes \\
\hline \multicolumn{4}{|c|}{ Part A: Technical Risk Screening Criteria } \\
\hline \multicolumn{4}{|l|}{ TECHNOLOGY } \\
\hline \multicolumn{4}{|l|}{ 1. New Technology? } \\
\hline \multicolumn{4}{|l|}{ 2. Unknown or unclear technology? } \\
\hline \multicolumn{4}{|c|}{ 3. New application of existing technology? } \\
\hline \multicolumn{4}{|c|}{ 4. Modernized/advanced technology in existing application? } \\
\hline \multicolumn{4}{|c|}{ PHYSICAL INTERFACES/INTERFACE CONTROL } \\
\hline \multicolumn{4}{|l|}{ 1. Multiple system interfaces? } \\
\hline \multicolumn{4}{|l|}{ 2. Multiple technical agencies? } \\
\hline \multicolumn{4}{|c|}{ 3. Interface with operating structures, systems, or components during installation? } \\
\hline \multicolumn{4}{|l|}{ SAFETY } \\
\hline \multicolumn{4}{|l|}{ 1. Criticality potential? } \\
\hline \multicolumn{4}{|c|}{ 2. Significant exposure/contamination potential? } \\
\hline \multicolumn{4}{|c|}{ 3. Any impact to facility's authorization basis? } \\
\hline \multicolumn{4}{|l|}{ 4. Hazardous material involved? } \\
\hline \multicolumn{4}{|l|}{ 5. Process hazard potential? } \\
\hline \multicolumn{4}{|c|}{$\begin{array}{l}\text { 6. Will hazardous materials inventories exceed OSHA or Radiation Management Plan total } \\
\text { quantities? }\end{array}$} \\
\hline \multicolumn{4}{|l|}{ REGULATORY/ENVIRONMENTAL } \\
\hline \multicolumn{4}{|c|}{ 1. Environmental assessment/impact statement? } \\
\hline \multicolumn{4}{|l|}{ 2. Additional releases? } \\
\hline 3. Undefined disposal methods? & & & \\
\hline
\end{tabular}


APPENDIX B

(continued)

\begin{tabular}{|c|c|c|c|}
\hline \multirow{2}{*}{ Risk Screening Criteria } & \multicolumn{3}{|c|}{ Potential for Risk? } \\
\hline & No & Low & Yes \\
\hline \multicolumn{4}{|l|}{ SAFEGUARDS AND SECURITY } \\
\hline \multicolumn{4}{|l|}{ 1. Category I nuclear material? } \\
\hline \multicolumn{4}{|l|}{ 2. Classified process/information? } \\
\hline \multicolumn{4}{|l|}{ DESIGN } \\
\hline \multicolumn{4}{|c|}{ 1. Undefined, incomplete, or unclear functional requirements? } \\
\hline \multicolumn{4}{|l|}{ 2. Undefined, incomplete, or unclear design criteria? } \\
\hline \multicolumn{4}{|l|}{3 Complex design features? } \\
\hline \multicolumn{4}{|l|}{ 4. Difficult to perform functional test? } \\
\hline \multicolumn{4}{|l|}{ 5. Numerous or unclear assumptions? } \\
\hline \multicolumn{4}{|l|}{ RESOURCES/CONDITIONS } \\
\hline \multicolumn{4}{|l|}{ 1. Adequate and timely resources not available? } \\
\hline \multicolumn{4}{|l|}{ 2. Specialty resources required? } \\
\hline \multicolumn{4}{|l|}{ OTHER (define below) } \\
\hline \multicolumn{4}{|l|}{1.} \\
\hline \multicolumn{4}{|l|}{2.} \\
\hline \multicolumn{4}{|l|}{ Part B: Project Risk Screening Criteria } \\
\hline \multicolumn{4}{|l|}{ Cost } \\
\hline \multicolumn{4}{|l|}{ Modification TPC $>\$ 4$ million } \\
\hline \multicolumn{4}{|l|}{ SCHEDULE } \\
\hline Uncertainties or restraints that may impact project com & & & \\
\hline
\end{tabular}


NNSA/NV-781

\section{APPENDIX B}

(continued)

\begin{tabular}{|c|c|c|c|}
\hline \multirow{2}{*}{ Risk Screening Criteria } & \multicolumn{3}{|c|}{ Potential for Risk? } \\
\hline & No & Low & Yes \\
\hline \multicolumn{4}{|l|}{ PROCUREMENT } \\
\hline \multicolumn{4}{|l|}{ 1. Long-lead items may affect critical path? } \\
\hline \multicolumn{4}{|l|}{ 2. Potential unavailable qualified vendors or contractors? } \\
\hline \multicolumn{4}{|l|}{ PROGRAMMATIC INTERFACES } \\
\hline \multicolumn{4}{|l|}{ 1. Significant transportation or infrastructure impacts? } \\
\hline \multicolumn{4}{|l|}{ 2. Multiple project interface? } \\
\hline \multicolumn{4}{|l|}{ 3. Multiple contractor interface? } \\
\hline \multicolumn{4}{|l|}{ 4. Significant interface with operational facility? } \\
\hline \multicolumn{4}{|l|}{ REGULATORY/ENVIRONMENTAL } \\
\hline \multicolumn{4}{|l|}{ 1. Political visibility? (DOE, local government, Congress) } \\
\hline \multicolumn{4}{|l|}{ OTHER (define below) } \\
\hline \multicolumn{4}{|l|}{1.} \\
\hline 2. & & & \\
\hline
\end{tabular}




\section{APPENDIX C - RISK CATEGORY LIST}

Note: This list is not all-inclusive, but provides a typical checklist of risk categories.

\section{TECHNICAL CATEGORIES}

Design

Undefined, Incomplete, Unclear Functions or

Requirements

Complex Design Features

Numerous or Unclear Assumptions or Bases

Reliability

Inspectability

Maintainability

Safety Class

Availability

Errors and Omissions in Design

\section{Construction Strategy}

Turnover/Start-up Strategy

Direct Hire/Subcontract

Construction/Maintenance Testing

Design Change Package Issues

\section{Regulatory and Environmental}

Environmental Impact Statement required

Additional Releases

Undefined Disposal Methods

Permitting

State Inspections

Order Compliance

Regulatory Oversight

Technology

New Technology

Existing Technology Modified

New Application of Existing Technology

Unknown or Unclear Technology

Testing

Construction

Maintenance

Operability

Facility Start-up

System Start-up (Subcontractor or PE\&CD)

\section{Safety}

Criticality Potential

Fire Watch

Exposure Contamination Potential

Authorization Basis Impact

Hazardous Material Involved

Emergency Preparedness

Safeguards and Security

Category I Nuclear Materials

Classified Process/Information

Confinement Strategies

$\underline{\text { Interfaces }}$

Multiple Agencies, Contractors

Special Work Control/Work Authorization Procedures

Operating SSCs Including Testing
Multiple Customers

Co-Occupancy

Outage Requirements

Multiple Systems

Radiological Conditions (current and future) Contamination

Radiation

Multiple Projects

Proximity to Safety Class Systems

PROGRAMMATIC CATEGORIES

Programmatic

Funding Uncertainties

Stakeholders Program Strategy Changes

Fast Track/Critical Need Infrastructure Influence

Schedule Deferrals

Schedule Acceleration

Management acceptance of risk w/o mitigation

\section{Procurement}

Procurement Strategy

First-Use Subcontractor/Vendor

Vendor Support

Resource/Conditions

Material/Equipment Availability

Specialty Resources Required

Existing Utilities Above and Underground

Support Services Availability

Geological conditions

Temporary Resources (Power, Lights, Water, etc.)

Resources Not Available

Construction Complexities

Transportation

Critical Lifts

Population Density

Escorts

Personnel Training and Qualifications

Tools, Equipment Controls, and Availability

Experience with System/Component (Design,

Operations, Maintenance)

Work Force Logistics

OPC Resources

Operations Support

Health Physics

Facility Support

Facility Maintenance Centralized Maintenance

Construction Support Post Modifications

Research and Development Support

Unique Working Conditions

Personnel Injury

Personnel Protection

Vehicular 
NNSA/NV-781

Risk Management Plan

Rev. 0

Ergonomics

Weather/Climate Conditions

Other

Schedule

Cost

Errors and Omissions in Estimates

Scope Change

Security 


\section{APPENDIX D - RISK ANALYSIS PROCESS}

\section{Step 1: Determine Probability}

\begin{tabular}{|c|c|c|}
\hline \multicolumn{2}{|c|}{ Probability of Occurrence } & \multirow{2}{*}{ Typical Criteria $^{1}$} \\
\hline Quantitative & Qualitative & \\
\hline$\leq 0.1$ & $\begin{array}{c}\text { Very } \\
\text { Unlikely }\end{array}$ & $\begin{array}{l}\text { Will not likely occur anytime in the life cycle of the project; or estimated } \\
\text { occurrence interval > 10,000 years; or the probability of occurrence is } \leq \\
10 \% \text {. }\end{array}$ \\
\hline $\begin{array}{l}>0.1 \text { but }< \\
\quad 0.4\end{array}$ & Unlikely & $\begin{array}{l}\text { Will not likely occur in the life cycle of the project or its facilities; or } \\
\text { estimated recurrence interval exceeds } 1,000 \text { years; or the probability of } \\
\text { occurrence is }>10 \% \text { but } \leq 40 \% \text {. }\end{array}$ \\
\hline $\begin{array}{l}>0.4 \text { but }< \\
\quad 0.8\end{array}$ & Likely & $\begin{array}{l}\text { Will likely occur sometime during the life cycle of the project or its } \\
\text { facilities; or estimated recurrence interval is between } 10 \text { to } 1,000 \text { years; } \\
\text { or the probability of occurrence is }>40 \% \text { but }<80 \% \text {. }\end{array}$ \\
\hline$>0.8$ & $\begin{array}{l}\text { Very } \\
\text { Likely }^{2}\end{array}$ & $\begin{array}{l}\text { Will likely occur sometime during the life cycle of the project; or } \\
\text { estimated recurrence interval is less than } 10 \text { years; or the probability of } \\
\text { occurrence is } \geq 80 \% \text {. }\end{array}$ \\
\hline
\end{tabular}

Criteria time intervals subject to project-specific needs.

${ }^{2}$ FOAK Risk Probability will always be qualified in this range unless substantiated otherwise.

Step 2: Determine Consequence

\begin{tabular}{|c|c|l|}
\hline \multicolumn{2}{|c|}{$\begin{array}{c}\text { Consequence of } \\
\text { Occurrence }\end{array}$} & \multicolumn{1}{c|}{ Typical Criteria ${ }^{1,2}$} \\
\hline \hline Qualitative & Quantitative & \\
\hline \hline 0.1 & Negligible & $\begin{array}{l}\text { Minimal or no consequences, unimportant; Some potential transfer of } \\
\text { money, but budget estimates not exceeded; Negligible impact on program } \\
\text { with slight potential for schedule change; compensated by available } \\
\text { schedule float. }\end{array}$ \\
\hline 0.2 to 0.4 & Marginal & $\begin{array}{l}\text { Small reduction in modification/project technical performance; Moderate } \\
\text { threat to facility mission, environment, or people with possibility of } \\
\text { requiring minor facility redesign or repair with moderate environmental } \\
\text { remediation or first aid/minor medical intervention; Cost estimates } \\
\text { marginally exceed budget; Moderate slip in schedule with some potential } \\
\text { adjustment to milestones required. }\end{array}$ \\
\hline 0.5 to 0.7 & Significant & $\begin{array}{l}\text { Significant degradation in modification/project technical performance; } \\
\text { Significant threat to facility mission, environment, or people requiring some } \\
\text { facility redesign or repair with significant environmental remediation or } \\
\text { causes injury requiring medical treatment; Cost estimates significantly } \\
\text { increase budget; Significant slip in schedule with resulting milestone } \\
\text { changes that may affect facility mission. }\end{array}$ \\
\hline
\end{tabular}




\begin{tabular}{|c|c|c|}
\hline \multicolumn{2}{|c|}{$\begin{array}{c}\text { Consequence of } \\
\text { Occurrence }\end{array}$} & \multirow[t]{2}{*}{ Typical Criteria ${ }^{1,2}$} \\
\hline Qualitative & Quantitative & \\
\hline 0.8 to 0.9 & Critical $^{3}$ & $\begin{array}{l}\text { Technical goals of modification/project cannot be achieved; Serous threat } \\
\text { to facility mission, environment or people with the possibility of completing } \\
\text { only portions of the mission, or requiring major facility redesign or } \\
\text { rebuilding, extensive environmental remediation, or intensive medical care } \\
\text { for life-threatening injury; Cost estimates seriously exceed budget; } \\
\text { Excessive schedule slip unacceptably affecting overall mission of } \\
\text { facility/site/DOE objectives. }\end{array}$ \\
\hline$>0.9$ & Crisis $^{3}$ & $\begin{array}{l}\text { Modification/project cannot be completed; Catastrophic threat to facility } \\
\text { mission, environment, or people possibly causing loss of mission with } \\
\text { long-term environmental abandonment and death; Cost estimates } \\
\text { unacceptably exceed budget. }\end{array}$ \\
\hline
\end{tabular}

${ }_{1}^{1}$ Any one or more of the criteria in the five levels of consequence may apply to a single risk. The consequence level for the risk being evaluated must be based upon the highest level for which a criterion applies.

${ }^{2}$ Actual dollar values and schedule delays to be determined per project-specific needs/limitations.

${ }^{3}$ FOAK Risk will always be qualified in this range unless substantiated otherwise.

\section{Step 3: Determine Risk Level}

A Risk factor is established by evaluating the probability and consequence for each risk event. Risk levels can be constructed qualitatively (by a risk level matrix) or quantitatively (by probability times consequence equation). In any case, the risk factor number, as depicted in the following table, corresponds with a risk level:

\begin{tabular}{|l|l|}
\hline Risk Factor & Risk Level \\
\hline \hline$<0.1$ & Low \\
\hline$\geq 0.1$ but $\leq 0.5$ & Moderate \\
\hline$>0.5$ & High \\
\hline
\end{tabular}




\section{Step 4: Determine Approach}

1. Qualitative Approach (Risk Level Matrix)

Address each risk statement from the risk assessment form individually to determine probability and consequence for each risk. A risk level is assigned based upon the intersection on the matrix. Depending upon the activity and the ability to differentiate the risk levels, other matrices may be chosen by the risk analysis team.

A typical risk level matrix is depicted as follows:

\begin{tabular}{|c|c|c|c|c|c|}
\hline \multirow{5}{*}{ 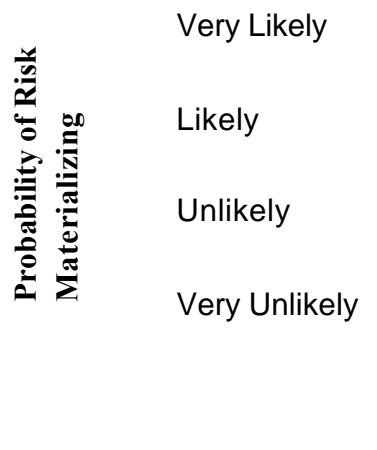 } & Low & Moderate & High & High & High \\
\hline & Low & Moderate & High & High & High \\
\hline & Low & Low & Moderate & Moderate & High \\
\hline & Low & Low & Low & Low & High \\
\hline & Negligible & Marginal & Significant & Critical & Crisis \\
\hline
\end{tabular}

2. Quantitative Approach

a. Address each risk statement from the risk assessment form individually.

b. Determine probability $(\mathrm{P})$ of occurrence for each risk with appropriate basis and justification.

c. Determine consequence $(\mathrm{C})$ of occurrence for each risk with appropriate basis and justification.

d. Use formula risk factor $=\mathrm{P}$ X C to determine risk factor for each identified risk.

e. Based on the value, determine the risk level (i.e., high, moderate, or low) for each identified risk.

Both approaches use the risk assessment form as documentation of the above steps. 